\title{
Atomic scale reversible opto-structural switching of few atom luminescent silver clusters confined in LTA zeolites
}

\author{
Saleh Aghakhani, ${ }^{a}$ Didier Grandjean, ${ }^{* a}$ Wouter Baekelant, ${ }^{\mathrm{b}}$ Eduardo Coutiño-Gonzalez, ${ }^{\mathrm{b}, \mathrm{c}}$ Eduard Fron, ${ }^{\mathrm{b}}$ \\ Kristina Kvashnina, ${ }^{d, e}$ Maarten B. J. Roeffaers, ${ }^{f}$ Johan Hofkens, ${ }^{b}$ Bert F. Sels, ${ }^{f}$ and Peter Lievens ${ }^{a}$ \\ aDepartment of Physics and Astronomy, Laboratory of Solid State Physics and Magnetism, KU Leuven, Celestijnenlaan 200D, \\ 3001 Leuven, Belgium. 'beuven Chem \&Tech: Molecular Imaging and Photonics (MIP), KU Leuven, Celestijnenlaan $200 \mathrm{~F}, 3001$ \\ Leuven, Belgium. 'CONACYT - Centro de Investigación y Desarrollo Tecnológico en Electroquímica, Parque Industrial Querétaro, \\ Sanfandila s/n, Pedro Escobedo 76703, Querétaro, Mexico. d Rossendorf Beamline at ESRF-The European Synchrotron, CS40220, \\ 38043 Grenoble Cedex 9, France. eHelmholtz Zentrum Dresden-Rossendorf (HZDR), Institute of Resource Ecology, PO Box \\ 510119, 01314 Dresden, Germany. 'DUBBLE CRG-ESRF- The European Synchrotron, CS 40220, 38043 Grenoble Cedex 9, France. \\ gLeuven Chem \&Tech: Centre for Surface Chemistry and Catalysis (COK), KU Leuven, Celestijnenlaan 200F, 3001 Leuven, \\ Belgium.
}

\section{Content}

Figures S1 to S5

Table S1

Additional text on NIR-DRS, XAFS, FTIR and ESR analysis

References 


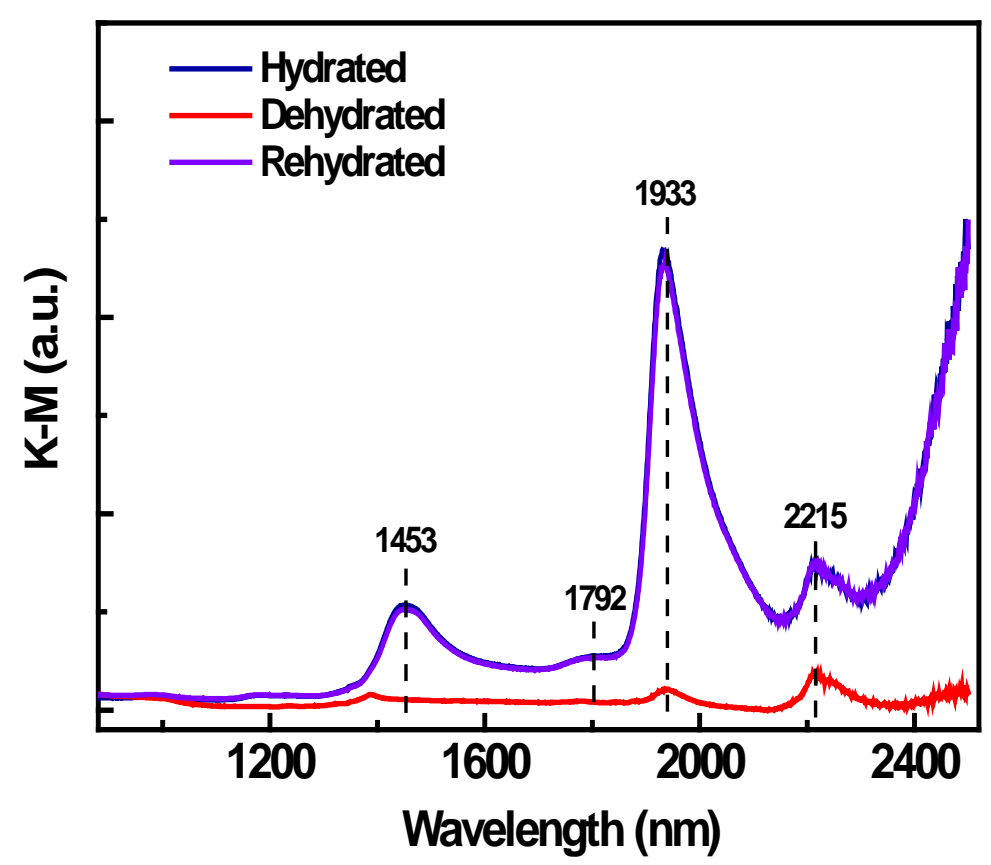

Figure S1. NIR DRS spectra of sample in different hydration states.

\section{NIR DRS Spectroscopy Analysis}

Figure S1 presents the assignment of the overtone and combination vibrational bands of water and hydroxyls in the sodalite in the NIR range. These attenuated bands are complementary to the FTIR results for the identification of the different water and hydroxyl types appearing in the material according to the water content. Three important NIR bands can be assigned as follows: A). Overtone of the hydroxyl vibration $\left[\left(2 * \mathrm{v}_{\mathrm{s}} \mathrm{OH}\right)\right]$ at $1450-1475 \mathrm{~nm}$ (depending on the type of $\mathrm{OH}$ group), B). Combination of the water and hydroxyl vibration $\left[\left(\mathrm{v}_{\mathrm{s}}+\mathrm{v}_{\delta}\right) \mathrm{H}_{2} \mathrm{O}\right]$ at $1900-1950 \mathrm{~nm}$ (depending on the type of zeolitic water and its interaction with the (non)-framework atoms), and C). Combination of symmetric and bending vibration of Si-O(H)-Al $\left[\left(\mathrm{V}_{\mathrm{s}}+\mathrm{v}_{\delta}\right) \mathrm{Si}-\mathrm{O}(\mathrm{H})-\mathrm{Al}\right]$ around $2215 \mathrm{~nm} .{ }^{1}$ These bands appear only in the presence of water, except the band at $2215 \mathrm{~nm}$, which remains almost constant upon dehydration. This might be related to the major contribution of structural Si-O-Al vibrations in the absence of significant hydroxyls. 

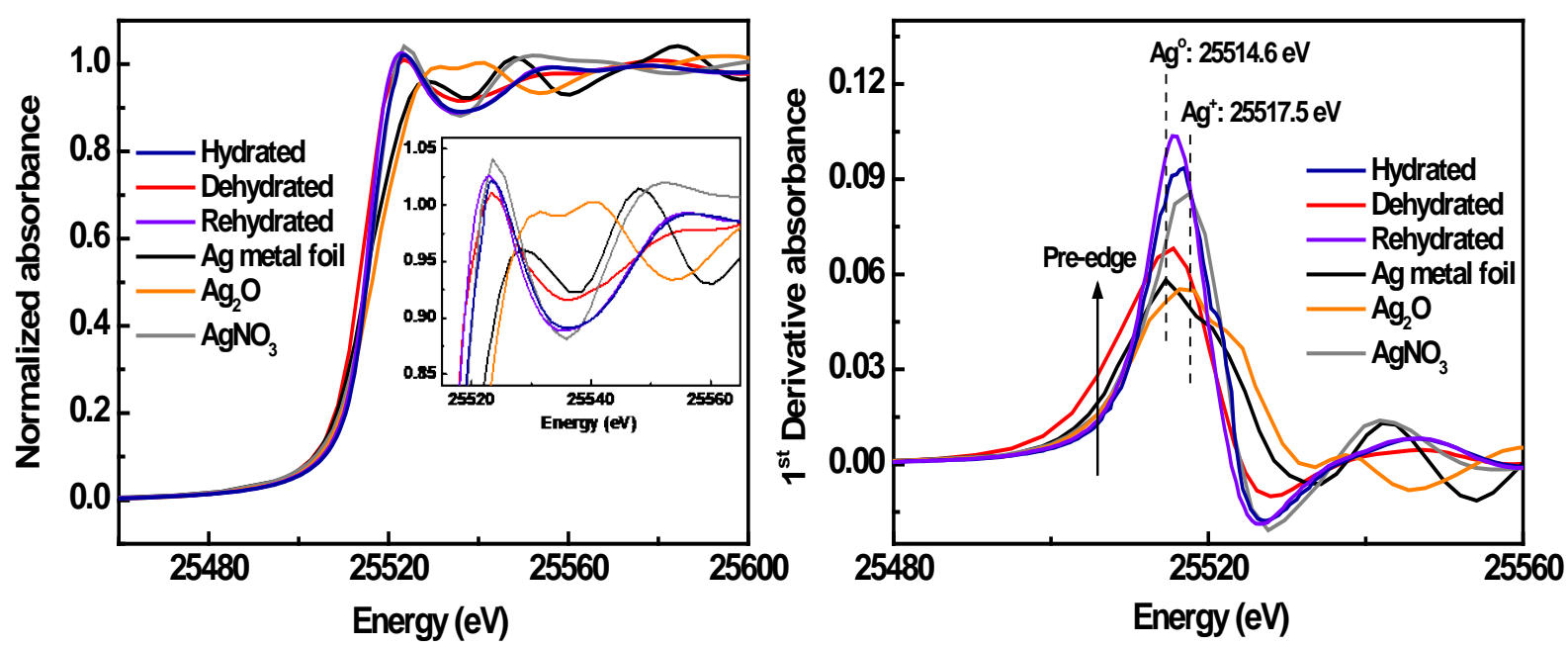

Figure S2. Ag K-edge A). Normalized and B). First derivative XANES spectra of a $\mathrm{Ag}_{3}$ NagLTA sample in different hydration states compared to $\mathrm{Ag}$ metal foil $\left(\mathrm{Ag}^{\circ}\right), \mathrm{Ag}_{2} \mathrm{O}\left(\mathrm{Ag}^{+}\right)$, and $\mathrm{AgNO}_{3}\left(\mathrm{Ag}^{+}\right)$reference. The $\mathrm{Ag}$ edge position of references are indicated in profile $B$ for better clarification of the sample charge in each hydration state.

\section{XANES}




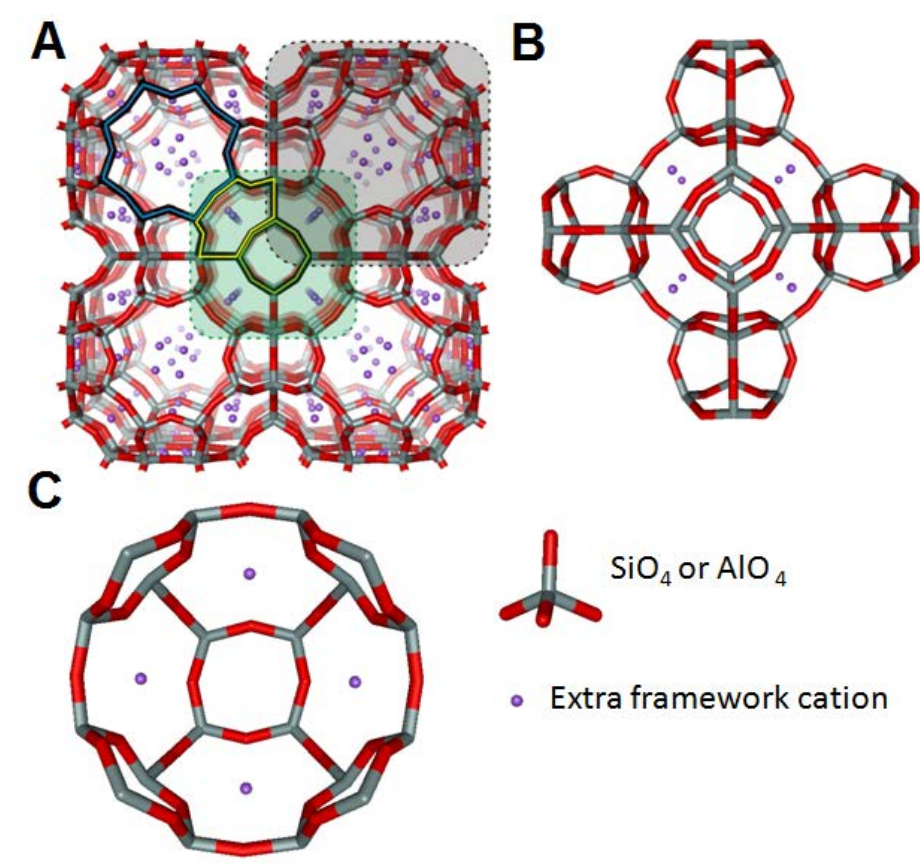

Figure S3. Schematic representation of A) LTA unit cell displaying the sodalite (green dashed area) and super cage (gray dashed area); the eight ring (8R), single six ring (S6Rs), and double four rings (D4Rs) are highlighted in blue, yellow and green respectively, B) Isolated sodalite cage with D4R connectors, and C) Transversal section of a sodalite cage.

\section{LTA Zeolite Unite Cell}

\section{EXAFS}

Details of the EXAFS fitting parameters are given in Table S1. Based on AgCLs in LTA crystallographic data $^{2-4}$ and clarify better the nature of $\mathrm{Ag}$ atoms, two distinct geometrical positions are taken into account: I). Ag atoms forming $\mathrm{AgCLs}\left(\mathrm{Ag}_{\mathrm{c}}\right)$ located inside the sodalite and II). $\mathrm{Ag}$ cations occupying the sodalite $\mathrm{S} 6 \mathrm{Rs}\left(\mathrm{Ag}_{6 \mathrm{R}}\right) . \mathrm{Ag}_{\mathrm{c}}$ and $\mathrm{Ag}_{6 \mathrm{R}}$ fractions are then required to calculate the coordination number $\left(\mathrm{CN}_{\mathrm{i}}\right)$ of each shell. The $\mathrm{Ag}_{6 R}$ fraction is obtained from the $\mathrm{Ag}_{6 R} \mathrm{CN}$ with the $(\mathrm{Si} / \mathrm{Al})_{6 R}$ divided by six $\left(\mathrm{CN}_{5} / 6\right.$, Table S1) as the maximum $\mathrm{CN}$ to $\mathrm{Si}$ or $\mathrm{Al}$ atoms in the $\mathrm{S} 6 \mathrm{Rs}$. Then, $\mathrm{The} \mathrm{Ag}_{\mathrm{C}}$ fraction is simply derived by considering that $A g_{c}+A g_{6 R}=1$. These fractions are tabulated in Table S1.

Table S1. Summary of Ag-K edge EXAFS structural refinements of samples with different hydration state. 


\begin{tabular}{|c|c|c|c|c|c|c|c|c|c|c|}
\hline \multirow[b]{2}{*}{$\mathbf{N}_{\mathrm{i}}$} & \multirow[b]{2}{*}{ Shell } & \multicolumn{3}{|c|}{ Hydrated } & \multicolumn{3}{|c|}{ Dehydrated } & \multicolumn{3}{|c|}{ Rehydrated } \\
\hline & & $\mathrm{CN}_{\mathrm{i}}$ & $\mathbf{R}_{\mathrm{i}}(\AA)$ & $A_{i}\left(\AA^{2}\right)$ & $\mathrm{CN}_{\mathrm{i}}$ & $\mathbf{R}_{\mathbf{i}}(\AA)$ & $A_{i}\left(\AA^{2}\right)$ & $\mathrm{CN}_{\mathrm{i}}$ & $\mathbf{R}_{\mathrm{i}}(\stackrel{\mathrm{A})}{\mathrm{C}}$ & $A_{i}\left(\AA^{2}\right)$ \\
\hline 1 & $A g_{C+6 R}-0$ & $2.6(5)$ & $2.33(2)$ & $0.025(3)$ & $1.8(3)$ & $2.27(1)$ & $0.018(2)$ & $2.6(2)$ & $2.33(2)$ & $0.024(2)$ \\
\hline 2 & $\mathrm{Ag}_{\mathrm{c}}-\mathrm{Ag}_{\mathrm{c}}$ & $2.0(4)$ & $2.72(3)$ & $0.041(3)$ & $1.5(3)$ & $2.75(6)$ & $0.072(6)$ & $1.9(4)$ & $2.73(2)$ & $0.040(3)$ \\
\hline 3 & $\mathrm{Ag}_{c}-\mathrm{O}$ & $0.4(2)$ & $3.17(2)$ & $0.038(4)$ & $0.9(2)$ & $2.81(4)$ & $0.035(4)$ & $0.4(2)$ & $3.18(1)$ & $0.035(3)$ \\
\hline 4 & $\mathrm{Ag}_{6 \mathrm{R}}-(\mathrm{Si} / \mathrm{Al})$ & $2.0(4)$ & $3.29(2)$ & $0.018(2)$ & $3.7(6)$ & $3.25(1)$ & $0.024(4)$ & $2.1(4)$ & $3.27(2)$ & $0.016(2)$ \\
\hline 5 & $\mathrm{Ag}_{\mathrm{c}}-\mathrm{Na}$ & $0.5(3)$ & $3.24(3)$ & $0.015(2)$ & $0.5(2)$ & $3.01(3)$ & $0.025(3)$ & $0.3(1)$ & $3.19(3)$ & $0.008(1)$ \\
\hline \multirow[t]{2}{*}{6} & $\mathrm{Ag}_{\mathrm{c}}-\mathrm{Ag}_{6 \mathrm{R}}$ & $0.4(2)$ & $3.42(2)$ & $0.023(3)$ & $0.6(2)$ & $3.40(3)$ & $0.021(2)$ & $1.2(3)$ & $3.41(2)$ & $0.033(2)$ \\
\hline & & \multicolumn{2}{|c|}{$\begin{array}{r}\mathrm{Ag}_{\mathrm{c}}: \mathrm{Ag}_{6 \mathrm{R}} \\
66 \%: 34 \%\end{array}$} & $R^{*}=19.50 \%$ & \multicolumn{2}{|c|}{$\begin{array}{r}\mathrm{Ag}_{\mathrm{c}}: \mathrm{Ag}_{6 \mathrm{R}} \\
38 \%: 62 \%\end{array}$} & $R^{*}=23.76 \%$ & \multicolumn{2}{|c|}{$\begin{array}{r}\mathrm{Ag}_{\mathrm{c}}: \mathrm{Ag}_{6 \mathrm{R}} \\
65 \%: 35 \%\end{array}$} & $R^{*}=16.76 \%$ \\
\hline
\end{tabular}

$\mathbf{N}_{\mathbf{i}}$ : Shell number, $\mathbf{C N}_{\mathbf{i}}$ : Coordination number of atom in the $\mathrm{N}_{\mathrm{i}}^{\text {th }}$ shell, $\mathbf{R}_{\mathbf{i}}$ : Radial distance of atoms in the $\mathrm{N}_{\mathrm{i}}^{\text {th }}$ shell $[\AA]], \mathbf{A}_{i}$ : Debye-Waller term of the $N_{i}^{\text {th }}$ shell $\left(A=2 \sigma^{2}\right.$ with $\sigma^{2}=$ Debye-Waller factor $)\left[\AA^{2}\right], \mathbf{R}^{*}:$ Error factor (\%) $\mathbf{A g} \mathbf{c}: A g$ atom composed of $\mathrm{AgCLs}, \mathrm{Ag}_{6 \mathrm{R}}$ : $\mathrm{Ag}$ cation coordinated with the six memberd ring, $\mathbf{A g}_{\mathrm{c}}: \mathbf{A g}_{6 \mathrm{R}}$ percentage of the $\mathrm{Ag}_{\mathrm{c}}$ and the $\mathrm{Ag}_{6 \mathrm{R}}$ in each EXAFS model.

Fitting the data with a six-shell model (Table S1) showed a good agreement with the 3D crystallographic model of LTA sodalite cage. Hydrated and rehydrated samples could be fitted with a very similar model consisting of a first shell $\left(\mathrm{N}_{1}\right)$ corresponding in both states to $2.6 \mathrm{O}$ located at $2.33 \AA$. This shell corresponds to a mixture of single cations $\mathrm{Ag}_{6 \mathrm{R}}$ located on the axis of the S6Rs of the sodalite cage coordinated to framework $\mathrm{O}_{6 \mathrm{R}}$ and $\mathrm{Ag}_{\mathrm{c}}$ forming clusters that are coordinated to extra-framework water $\left(\mathrm{O}_{\mathrm{w}}\right)$. Furthermore, the $\mathrm{Ag}_{6 \mathrm{R}}-\mathrm{O}_{6 \mathrm{R}}$ distance is shorther than the sum of $\mathrm{Ag}^{+}$and $\mathrm{O}^{2-}$ radii $(2.58 \AA)^{2}$ which is attributed to the covalent bond nature of the $\mathrm{Ag}_{6 \mathrm{R}}-\mathrm{O}_{6 \mathrm{R}}$ bond. $\mathrm{Ag} 6 \mathrm{R}$ are also coordinated to Si/Al atoms from the S6Rs at a distance of 3.27-3.29 $\AA$ forming shell $\left(\mathrm{N}_{4}\right)$. As $A g_{6 \mathrm{R}}$ are coordinated to $6 \mathrm{Si} / \mathrm{Al}$ and $3 \mathrm{O}$ implying a 2:1 $\mathrm{CN}$ ratio ${ }^{2,3}, \mathrm{CN}_{4}$ can be used to determine both $\mathrm{Ag}_{6 \mathrm{R}} / \mathrm{Ag}_{\mathrm{C}}$ and the $\mathrm{O}_{\mathrm{w}} / \mathrm{O}_{6 \mathrm{R}}$ ratio. $\mathrm{CN}_{4}$ of 2 and 2.1 in hydrated and rehydrated sample, respectively, indicate a similar $\mathrm{Ag}_{6 \mathrm{R}}$ fraction of $34 \%$ $(2.1 / 6 * 100)$ with the remaining part of $66 \%$ forming clusters $\mathrm{Ag}_{\mathrm{c} .}$. As $\mathrm{Ag}_{6 \mathrm{R}}$ in S6Rs are coordinated to 3.0 $\mathrm{O}_{6 \mathrm{R}}[0.34 * 3=1] 1 \mathrm{O}$ from shell $\mathrm{N} 1$ is an $\mathrm{O}_{6 \mathrm{R}}$ while the remaining $1.6 \mathrm{O}\left(\mathrm{CN}_{1}-1.0\right)$ is attributed to $\mathrm{O}_{\mathrm{w}}$ of water molecules that are coordinated with the $\mathrm{Ag}_{c}$ in the sodalite with an average $\mathrm{CN}$ of $\mathrm{Ag}_{c}-\mathrm{O}_{\mathrm{w}}: 2.4$ $\left[\left(C N_{1}-1.0\right) / 0.66\right]$. To extract the average $A g_{c}-O_{w}$ distance from the $R_{1}$, the average $A g_{6 R^{-}}-O_{6 R}$ and $A g_{6 R^{-}}$ $(\mathrm{Si} / \mathrm{Al})_{6 \mathrm{R}}$ distances of 2.30 and $3.28 \AA$ respectively were considered based on the crystallographic data of $\mathrm{Ag}_{12} \mathrm{LTA}^{3}$ Thus, the $\mathrm{Ag}_{\mathrm{c}}-\mathrm{O}_{\mathrm{w}}$ distance of $2.36 \AA$ can be simply derived by considering the contribution of $\mathrm{Ag}_{6 \mathrm{R}}-\mathrm{O}_{6 \mathrm{R}}$ and $\mathrm{Ag}_{\mathrm{c}}-\mathrm{O}_{\mathrm{w}}$ sub-shell in the first shell $[(2.6 * 2.33)=(1.6 * 2.36)+(1.0 * 2.30)]$. This estimated distance is in good agreement with reported XRD data $(2.40 \AA) .{ }^{4}$ 
The second shell $\left(\mathrm{N}_{2}\right)$ consists of intracluster $\mathrm{Ag}_{\mathrm{c}}-\mathrm{Ag}_{\mathrm{c}}$ interactions with distances of 2.72 and $2.73 \AA$ in the hydrated and rehydrated state respectively that are considerably shorter than typical Ag-Ag in $\mathrm{Ag}$ metal (2.89 $\AA$ ). ${ }^{4} \mathrm{Ag}_{\mathrm{c}}$ are coordinated with ca. 3.0 other $\mathrm{Ag}_{\mathrm{c}}\left(\mathrm{CN}_{2} / 0.66\right)$ forming tetrahedral $\mathrm{Ag}_{4}$ clusters. The average $\mathrm{CN} \mathrm{Ag} \mathrm{c}^{-} \mathrm{O}_{\mathrm{w}}$ of 2.4 suggests a mixture of ca. $80 \%\left[2.4 \mathrm{O}_{\mathrm{w}} /\left(2.4 \mathrm{O}_{\mathrm{w}}+0.6 \mathrm{O}_{6 \mathrm{R}}\right)\right]$ tetrahedral $\left[\mathrm{Ag}_{4}\left(\mathrm{H}_{2} \mathrm{O}\right)_{4}\right]$ and $20 \%(1-0.8)$ tetrahedral $\left[\mathrm{Ag}_{4}\left(\mathrm{O}_{6 \mathrm{R}}\right)_{2}\right]$ clusters.

The third shell $\left(N_{3}\right)$ with larger distance $\left(3.17 \AA, R_{3}\right)$ is related to the direct interaction of $A_{c}$ with the framework oxygen $\left(\mathrm{O}_{\mathrm{F}}\right)$ when water molecules are locally absent around the clusters. The large $\mathrm{Ag}_{\mathrm{c}}-\mathrm{O}_{\mathrm{F}}$ distance (3.17-3.18 $\left.\AA, \mathrm{R}_{3}\right)$ and small $\mathrm{CN}\left(0.6, \mathrm{CN}_{3} / 0.65\right)$ in the hydrated material can be found when tetrahedral $\mathrm{Ag}_{4}$ clusters are oriented along the S6Rs axis and partially interacting with the $\mathrm{O}_{6 \mathrm{R}}\left(\mathrm{CN}_{3}\right.$ compared to $\mathrm{CN}_{1}$ ). In this state, local dehydration induced by the X-Ray beam may explain the presence of this shell that was also observed in previous EXAFS studies..$^{5,6}$

$\mathrm{N}_{5}$ and $\mathrm{N}_{6}$ correspond to the long interaction between $\mathrm{Ag}_{\mathrm{C}}$ from the clusters and the cations located in the axis of the S6Rs of the sodalite cage. The $\mathrm{Ag}_{\mathrm{c}}-\mathrm{Na}$ shell $\left(\mathrm{N}_{5}\right)$ is attributed to the interaction of $\mathrm{Ag}_{\mathrm{c}}$ with Na co-cation residing on the axis of the S6Rs with a distance of 3.01-3.24 $\AA\left(\mathrm{R}_{4}\right)$, and $\mathrm{CN}_{5}$ 0.3-05 in the hydrated and rehydrated states respectively. In this structural configuration, a $\mathrm{Na}-\mathrm{O}_{\mathrm{F}}$ distance of $2.41-$ $2.50 \AA$ can be derived which is higher than the sum of $\mathrm{Na}^{+}$and $\mathrm{O}^{-2}$ radii $(2.29 \AA)^{2}$ and corresponds to an electrostatic interaction with $\mathrm{O}_{6 \mathrm{R}}$ unlike $\mathrm{Ag}_{6 \mathrm{R}}-\mathrm{O}_{6 \mathrm{R}}$ bond in the $\mathrm{S6Rs}$ that possesses a covalent character. Finally shell $\left(N_{6}\right)$ is assigned to long range (3.40-3.42 $\left.\AA, R_{6}\right)$ interaction of the $A g_{c}$ with the $A g_{6 R}$. The significant increase of $\mathrm{Ag}_{c}-\mathrm{Ag}_{6 \mathrm{R}} \mathrm{CN}_{6}$ (0.3-1.2) through rehydration probably indicates a redistribution of $\mathrm{Ag}$ and $\mathrm{Na}$ cations in the S6Rs around the clusters with a higher occupancy of the empty S6Rs by $\mathrm{Ag}_{6 \mathrm{R}}$ at the expense of $\mathrm{Na}$ cations whose coordination decreases from 0.5 to 0.3 in the rehydrated state. This is the only observed significant structural difference between the hydrated and rehydrated state.

Although the fitting model for the dehydrated state is very similar to the one used in the hydrated states marked differences appear. The first difference is observed in $\mathrm{CN}_{1}$ of the first $\mathrm{O}$ shell that 
significantly decreases from 2.6 in the (re)hydrated states to 1.8 in the dehydrated sample while the AgO bond distance shortens from 2.30 to $2.27 \AA ̊$ r reflecting the loss of water molecules around $\mathrm{Ag}_{\mathrm{c}}$ atoms.

The second difference is a significant decrease in $\mathrm{N}_{3}$ shell $\mathrm{Ag}_{\mathrm{c}}-\mathrm{O}_{\mathrm{F}}$ distance from 3.18 to $2.81 \AA$, $\mathrm{R}_{3}$ while $\mathrm{CN}_{3}$ remarkably increases to $2.4(0.9 / 0.38)$. This $\mathrm{Ag}_{\mathrm{c}}-\mathrm{O}_{\mathrm{F}}$ distance corresponds to $\mathrm{Ag}_{\mathrm{c}}$ atoms located on the axis of the S4Rs inside the sodalite cage that are now strongly interacting with $\mathrm{O}_{4 \mathrm{R}}$ atoms indicating that the position of the $\mathrm{AgCLs}$ relative to the sodalite cage has completely changed upon dehydration.

The large increase of $\mathrm{CN}_{4}$ of the Si/Al atoms shell from 2 in the (re)hydrated states to 3.7 indicates that a larger fraction of $\mathrm{Ag}_{\mathrm{R}}$ are now positioned on the axis of $\mathrm{S} 6 \mathrm{Rs}$ corresponding to a larger $\mathrm{Ag}_{\mathrm{R}}$ fraction $(3.7 / 6 * 100) 62 \%$ in the material. The fact that $N_{1}$ is exactly half the value of $N_{4}$ confirms that all the $O$ in $\mathrm{N}_{1}$ consist of $\mathrm{O}_{6 \mathrm{R}}$ and no water molecule are now present around the $\mathrm{Ag}_{\mathrm{c}}$.

Finally, the different values observed for the $\mathrm{N}_{2}$ shell corresponding to the $\mathrm{Ag}_{\mathrm{c}}-\mathrm{Ag}_{\mathrm{c}}$ interaction in the clusters with a lower $\mathrm{CN}_{2}$ of 1.5 and a larger $\mathrm{Ag}_{c}-\mathrm{Ag}_{\mathrm{c}}$ distance of $2.75 \AA$ are clearly an indication of the formation of larger AgCLs with an average coordination of $4\left(\mathrm{CN}_{2} / 0.38\right)$ corresponding to $\mathrm{Ag}_{6}$ clusters upon dehydration. These values are compatible with the transformation of tetrahedral $\mathrm{Ag}_{4}$ clusters coordinated to water molecules and located along $\mathrm{S} 6 \mathrm{Rs}$ axis into octahedral $\mathrm{Ag}_{6}$ clusters positioned along the S4Rs axis and coordinated only to $\mathrm{O}_{4 \mathrm{R}}$ atoms. The simulteous increase of AgCLs size and distance are in line with similar dehydrated AgCLs structures in Ag LTA that were identified by XRD ${ }^{4,7}$ and ESR. ${ }^{8}$ No major changes upon dehydration are observed for shells $\mathrm{N}_{5}$ and $\mathrm{N}_{6}$ corresponding to the long interaction between $\mathrm{Ag}_{\mathrm{c}}$ from the clusters and the cations located along the axis of the S6Rs of the sodalite cage.

\section{FTIR Analysis}


FTIR spectra of the $\mathrm{Ag}_{3} \mathrm{Na}_{9} \mathrm{LTA}$ zeolite in the mid-IR region $\left(4000-500 \mathrm{~cm}^{-1}\right.$, Figure S4A) are composed of the framework vibrational (T-O-T; $\mathrm{T}: \mathrm{Si}, \mathrm{Al})$, the water $\left(\mathrm{V}_{\delta} \mathrm{HOH}\right)$, and the hydroxyl $\left(\mathrm{V}_{\mathrm{s}} \mathrm{OH}\right)$ bands appearing in the spectral region of $1400-500,1700-1600$, and $3700-2900 \mathrm{~cm}^{-1}$, respectively. The T-O-T vibrations are divided into three main IR bands: the asymmetric vibrations of bridge bonds [ $\mathrm{V}_{\text {as }} \mathrm{Si}-\mathrm{O}-\mathrm{Si}$ (AI)] at $1006 \mathrm{~cm}^{-1}$, the symmetric vibrations of bridge bonds [V $\mathrm{Si}-\mathrm{O}-\mathrm{Si}(\mathrm{Al})$ ], and C) at 726 and $670 \mathrm{~cm}^{-1}$ and the symmetric stretching of vibrational bands formed by superposition of the 4Rs $6 R s$, and D4Rs ${ }^{9-11}$ appearing at $555 \mathrm{~cm}^{-1}$.
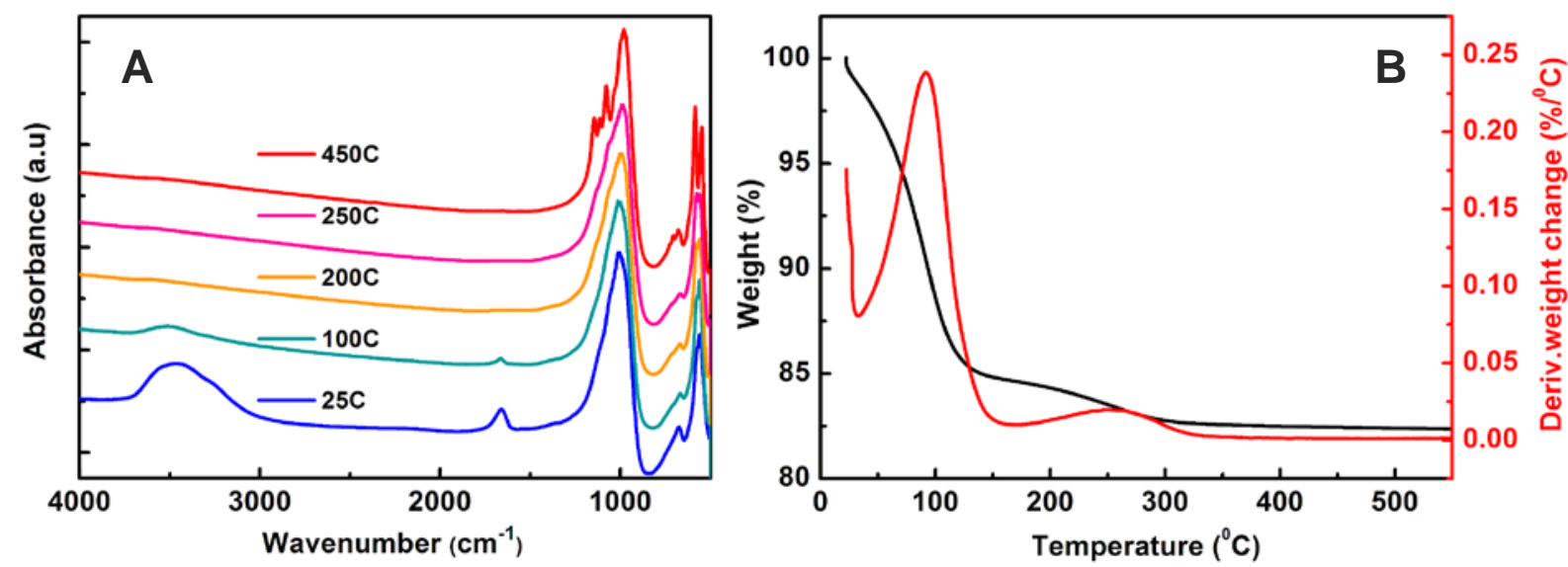

Figure S4. A). In-situ FTIR spectra of sample dehydrated in vacuum at different temperature B). TGA analysis of sample in nitrogen gas atmosphere.

The dehydration behaviour of $\mathrm{Ag}_{3} \mathrm{Na}_{9} \mathrm{LTA}$ was characterized both by FTIR and TGA analysis (Figure S4). According to the TGA result, most of the water is removed by dehydration at $100{ }^{\circ} \mathrm{C}(\sim 83 \%)$ while the remaining part is only eliminated at higher temperatures $\left(330^{\circ} \mathrm{C}\right)$. FTIR results show that the intensity of $\mathrm{v}_{\delta} \mathrm{HOH}$ and $\mathrm{v}_{\mathrm{s}} \mathrm{OH}$ significantly decreases up to $100{ }^{\circ} \mathrm{C}(\sim 75 \%$, in line with TGA results) and completely flattens out at $200{ }^{\circ} \mathrm{C}$. The dehydration rate is clearly faster in vacuum (FTIR) than in atmospheric nitrogen gas (TGA). T-O-T bands remain considerably unaltered in this temperature range. The emergence of new bands in this region is observed upon further dehydration above $200^{\circ} \mathrm{C}$. These bands become more pronounced when the dehydration temperature reaches $450{ }^{\circ} \mathrm{C}$ (dehydrated state). In parallel, the T-O-T bands are shifted, reaching the maximum band shift. 

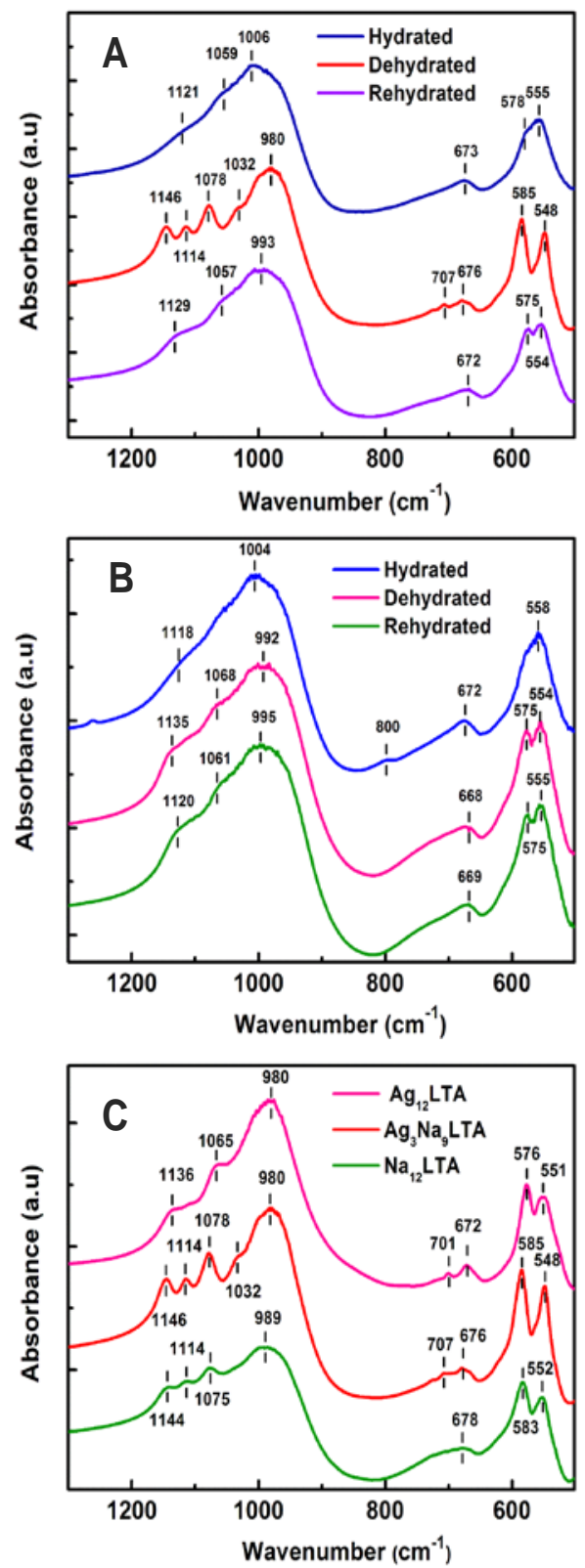

Figure S5. FTIR spectra of $\mathrm{Ag}_{3} \mathrm{Nag}$ LTA sample in different hydration states to monitor T-O-T (T=Si/Al) vibrational bands in A). Vacuum and B). Atmospheric oxygen gas condition. C). FTIR spectra of $\mathrm{Ag}_{3} \mathrm{Nag}_{\mathrm{L}} \mathrm{LTA}$ sample compared to parent LTA ( $\mathrm{Na}_{12} \mathrm{LTA}$ ) and fully loaded Ag LTA ( $\mathrm{Ag}_{12} \mathrm{LTA}$ ) zeolite in dehydrated state where the T-O-T distortion and shifted bands are at maximum.

The nature of these perturbations and band shifts (within 1200-900 $\mathrm{cm}^{-1}$ ) has been ascribed to the coordination of metal cations with the zeolite $\mathrm{O}_{\mathrm{F}}$ and the local electronic redistribution of the cationic sites, leading to a weakening of the T-O framework bonds, an elongation of the T-O distances, and a change of the T-O-T angles. ${ }^{12-14}$ Therefore, these results suggest that the loss of coordinated water from the cationic sphere of $\mathrm{Ag}$ and $\mathrm{Na}$ induces their stronger interaction and higher coordination degree with the $\mathrm{O}_{\mathrm{F}}$ which cause in turn T-O-T distortions and larger band shifts. ${ }^{15,16}$ 
T-O-T bands clearly observed through dehydration (Figure S5 A) intensify when reaching the fully dehydrated state $\left(450^{\circ} \mathrm{C}\right)$. Upon dehydration a stronger T-O-T distortion, new T-O-T bands formation, and larger T-O-T band shifts due to the higher interaction degree of the $\mathrm{Ag}$ and $\mathrm{Na}$ cations with the $\mathrm{O}_{\mathrm{F}}$ are observed. These distorted and shifted bands are not remarkable in an oxygen (Figure S5 B) environment, suggesting that these changes originate from the loss of coordinated water ligands and the lack of replaceable ligands. These bands relax upon rehydration due to the re-coordination of $\mathrm{Ag}$ and $\mathrm{Na}$ cations with water whose strong electron donation weakens the cation interaction with $\mathrm{O}_{\mathrm{F} .}{ }^{15,17 \text {, }}$ ${ }^{18}$ To assign separately the distorted and shifted T-O-T bands to specific location and interaction type with the $\mathrm{AgCLs}, \mathrm{Na}$, and $\mathrm{Ag}$ cations, the T-O-T vibrations of the $\mathrm{Ag}_{3} \mathrm{Na}_{9} \mathrm{LTA}$ sample are compared with parent LTA $\left(\mathrm{Na}_{12} \mathrm{LTA}\right)$ and fully loaded Ag LTA $\left(\mathrm{Ag}_{12} \mathrm{LTA}\right)^{19}$ in the dehydrated state (Figure S5 C). The distorted and shifted bands are less intense in $\mathrm{Ag}_{12} \mathrm{LTA}$ than in $\mathrm{Ag}_{3} \mathrm{Na}_{9} \mathrm{LTA}$ which can be attributed to the covalent rather than electrostatic interaction of the $\mathrm{Ag}$ cations with the $\mathrm{O}_{\mathrm{F}}$, leading to less $\mathrm{T}-\mathrm{O}-\mathrm{T}$ bonds distortion and shifting. ${ }^{12,16}$ These bands are less prounonced in $\mathrm{Na}_{12} \mathrm{LTA}$ than in $\mathrm{Ag}_{3} \mathrm{Nag}_{9} \mathrm{LTA}$, suggesting that the distortion and the energy shift mainly due to interaction of the $A g C L$ with $\mathrm{O}_{\mathrm{F}}$ (Figure $3 \mathrm{~B}$, column III) which do not exist in the parent $\mathrm{Na}_{12} \mathrm{LTA}$. Thus, the significantly distorted and shifted bands

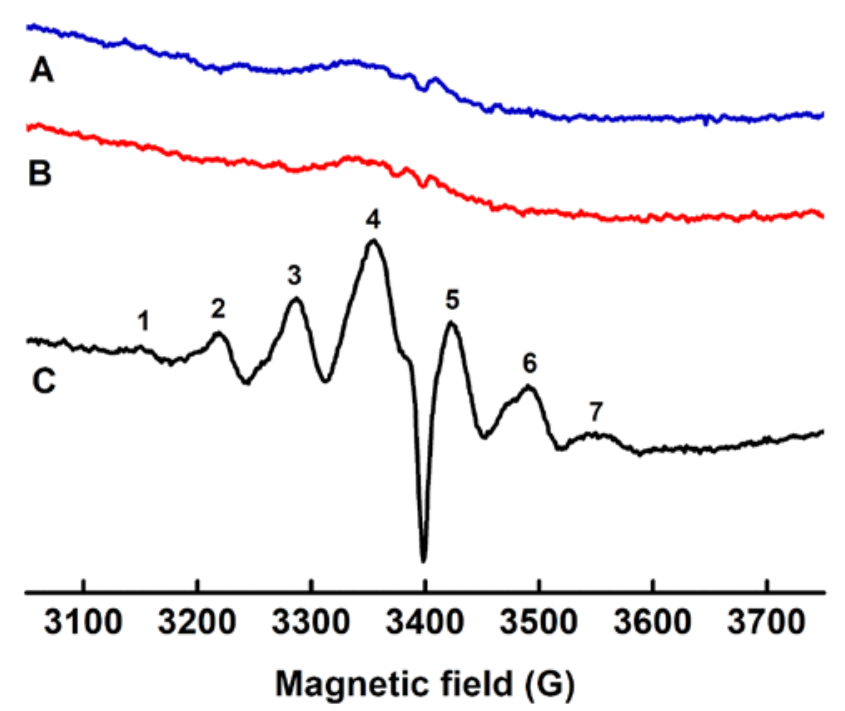

Figure S6. ESR spectra of the sample in (A) hydrated (B) dehydrated (C) dehydrated followed by $\mathrm{H}_{2}$ reduced state. $\mathrm{H}_{2}$ reduction performed on dehydrated sample at room temperature that exposed with a mixture of $5 \% \mathrm{H}_{2}$ in $\mathrm{N}_{2}$ gas during 90 min with the total gas flow rate of $50 \mathrm{ml} / \mathrm{min}$. 
in $\mathrm{Ag}_{3} \mathrm{Na}_{9} \mathrm{LTA}$ compared to $\mathrm{Na}_{12}$ and $\mathrm{Ag}_{12} \mathrm{LTA}$, could arise from the presence of both $\mathrm{Na} / \mathrm{Ag}$ cations and AgCLs perturbed T-O-T bonds. Since all the LTA framework vibrations (S6Rs, S4Rs, D4Rs and lattice) are part of the T-O-T vibrations and not separate into different vibrational modes, it is however difficult to unambiguously identify the exact location and interaction at the origin of the perturbation. ${ }^{20}$ Overall, FTIR shows that a strong interaction between extra-framework $\mathrm{AgCLs}, \mathrm{Na}$, and $\mathrm{Ag}$ cations and the framework oxygen $\left(\mathrm{O}_{\mathrm{F}}\right)$ is reversibly building up and decreasing upon dehydration and rehydration respectively in line with the results of the EXAFS analysis.

\section{ESR Analysis}
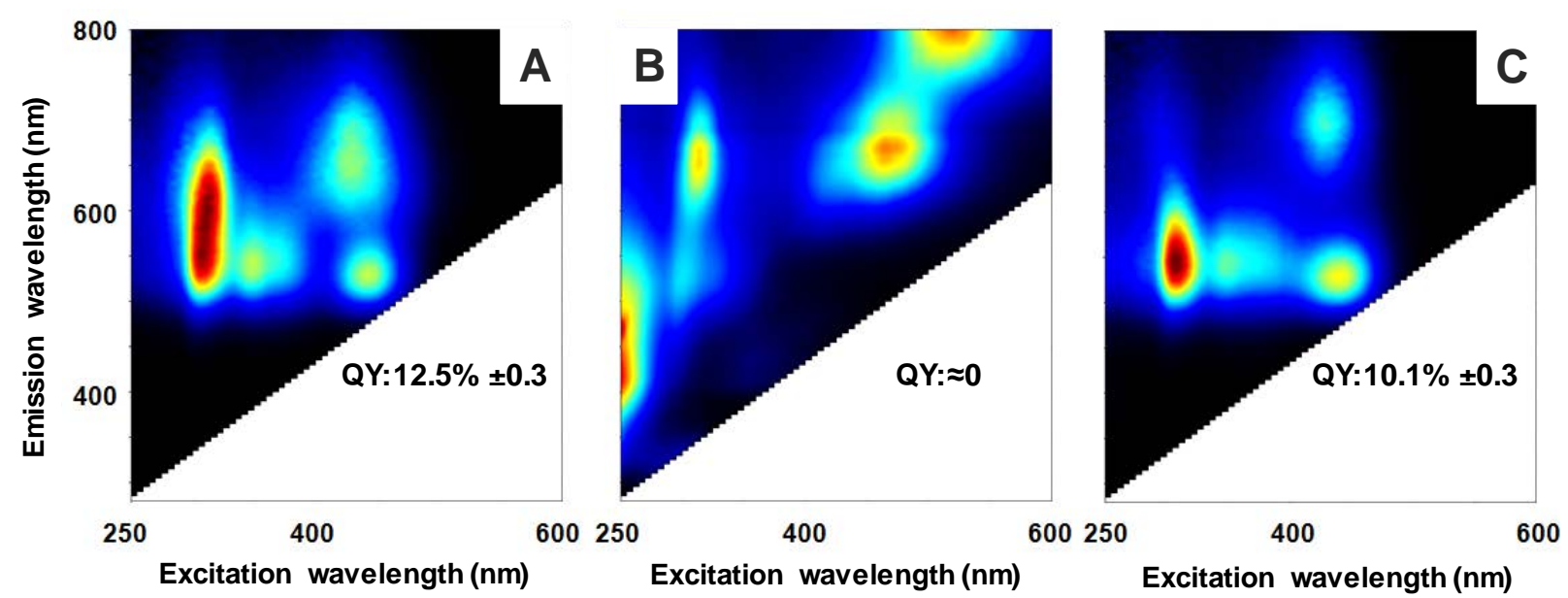

Figure S7. 2D excitation-emission plots of $\mathrm{Ag}_{3} \mathrm{~K}_{9} \mathrm{LTA}$ sample in A) Hydrated, B) Dehydrated, and C)

Rehydrated states. The insets show the QY \% of the samples at the maximum excitation of $310 \mathrm{~nm}$.

\section{References}

1. K. Beck, H. Pfeifer and B. Staudte, Microporous Mater., 1993, 2, 1-6.

2. Y. Kim and K. Seff, J Phys Chem 1987, 91, 671-674.

3. L. R. Gellens, W. J. Mortier, R. A. Schoonheydt and J. B. Uytterhoeven, J Phys Chem 1981, 85, 27832788.

4. K. Yang and K. Seff, J Am Chem Soc, 1978, 100, 6989-6997.

5. Y. Suzuki, T. Miyanaga, H. Hoshino, N. Matsumoto and T. Ainai, Phys Scr, 2005, 115, 765-768.

6. T. Miyanaga, H. Hoshino and H. Endo, J. Synchrotron Rad., 2001, 8, 557-559.

7. T. Sun and K. Seff, Chem. Soc. Rev., 1994, 94, 857-870.

8. T. Wąsowicz and J. Michalik, Int J Rad Appl Instrum 1991, 37, 427-432.

9. A. Mikula, M. Krol and A. Kolezynski, J Mol Model, 2015, 21, 275.

10. M. Krol, W. Mozgawa, W. Jastrzebski and K. Barczyk, Micropor Mesopor Mat, 2012, 156, 181-188.

11. W. Mozgawa, W. Jastrzebski and M. Handke, J Mol Struct, 2005, 744, 663-670.

12. B. B. Iversen, S. Latturner and G. Stucky, Chem. Mater., 1999, 11, 2912-2918. 
13. J. E. Sponer, Z. Sobalik, J. Leszczynski and B. Wichterlova, J Phys Chem B, 2001, 105, 8285-8290. 14. S. E. Latturner, J. Sachleben, B. B. Iversen, J. Hanson and G. D. Stucky, J Phys Chem B, 1999, 103, 7135-7144.

15. J. H. Kwaka, T. Vargab, C. H. F. Pedenc, F. Gaoc, J. C. Hansond and J. Szany, J Catal, 2014, 314, 83-93.

16. T. Carey, C. C. Tang, J. A. Hriljac and P. A. Anderson, Chem Mater, 2014, 26, 1561-1566.

17. E. Broclawik, J. Datka, B. Gil and P. Kozyra, Phys Chem Chem Phys, 2000, 2, 401-405.

18. Z. Sobalik, J. Dedecek, I. Ikonnikov and B. Wichterlova, Micropor Mesopor Mat, 1998, 21, 525-532.

19. O. Fenwick, E. Coutino-Gonzalez, D. Grandjean, W. Baekelant, F. Richard, S. Bonacchi, D. De Vos, P. Lievens, M. Roeffaers, J. Hofkens and P. Samori, Nat Mater, 2016, 15, 1017-1022.

20. J. A. Creighton, H. W. Deckman and J. M. Newsam, J Phys Chem, 1994, 98, 448-459. 